\title{
The use of a computer model in determining the nutrient requirement of pigs
}

\section{By C. T. Whiтtemore, Edinburgh School of Agriculture, West Mains Road, Edinburgh $\mathrm{EH}_{9} 3 \mathcal{}$ ҰG}

A computerized model for the determination of nutrient requirements of pigs may serve many purposes, including the development of ideas, interpretation of real life, prediction of response, transfer of information, scrutinization of existing knowledge, and the formulation of experimental programs. The type of model influences its value; deduction from first biological principles and identification of causal forces being the more rewarding, but the more difficult. Working hypotheses are particularly needed in the areas of factors influencing appetite, limits to lean tissue growth rate, the inter-relationships between fat and lean growth, and the influence of circumstance upon the energetic costs of protein deposition.

\section{Computer models for information transfer}

The word model implies some mechanism for the simulation of real animal response; it requires inputs, a means of processing them, and delivers outputs. They are often conveniently constructed in the form of a sequential arrangement of equations assigning values to variables (energy cost of maintenance $=X$, energy cost of protein deposition $=Y$ ), together with conditional statements (IF maximum rate of protein deposition is attained THEN divert energy to fat growth; WHEN house temperature is such as to require cold thermogenesis THEN increase maintenance allowance). It is this structuring which requires the help of a computer.

Models can encapsulate the entire range of current information about nutrient requirements. In this respect they serve as a library that the user does not require to read. Models cement together conventionally-separated disciplines and experimental results; for example, nutrient requirement and nutrient price. Because models short-circuit the necessity of the user understanding the scientific principles involved, they serve as a method for rapid transfer of experimental findings. Field advisers can thereby incept a comprehensive and complicated methodology for the determination of nutrient requirements. These advantages also predispose models to misuse. The model builder often must choose from a variety of plausible numerical values and hypotheses in order to formulate a methodology for determination of a nutrient requirement. The user is likely to be unaware that there were alternative values available, or that there were hypothetical aspects to the model.

$\infty 029-6651 / 80 / 3923-3808$ so1.00 (C) 1980 The Nutrition Society 


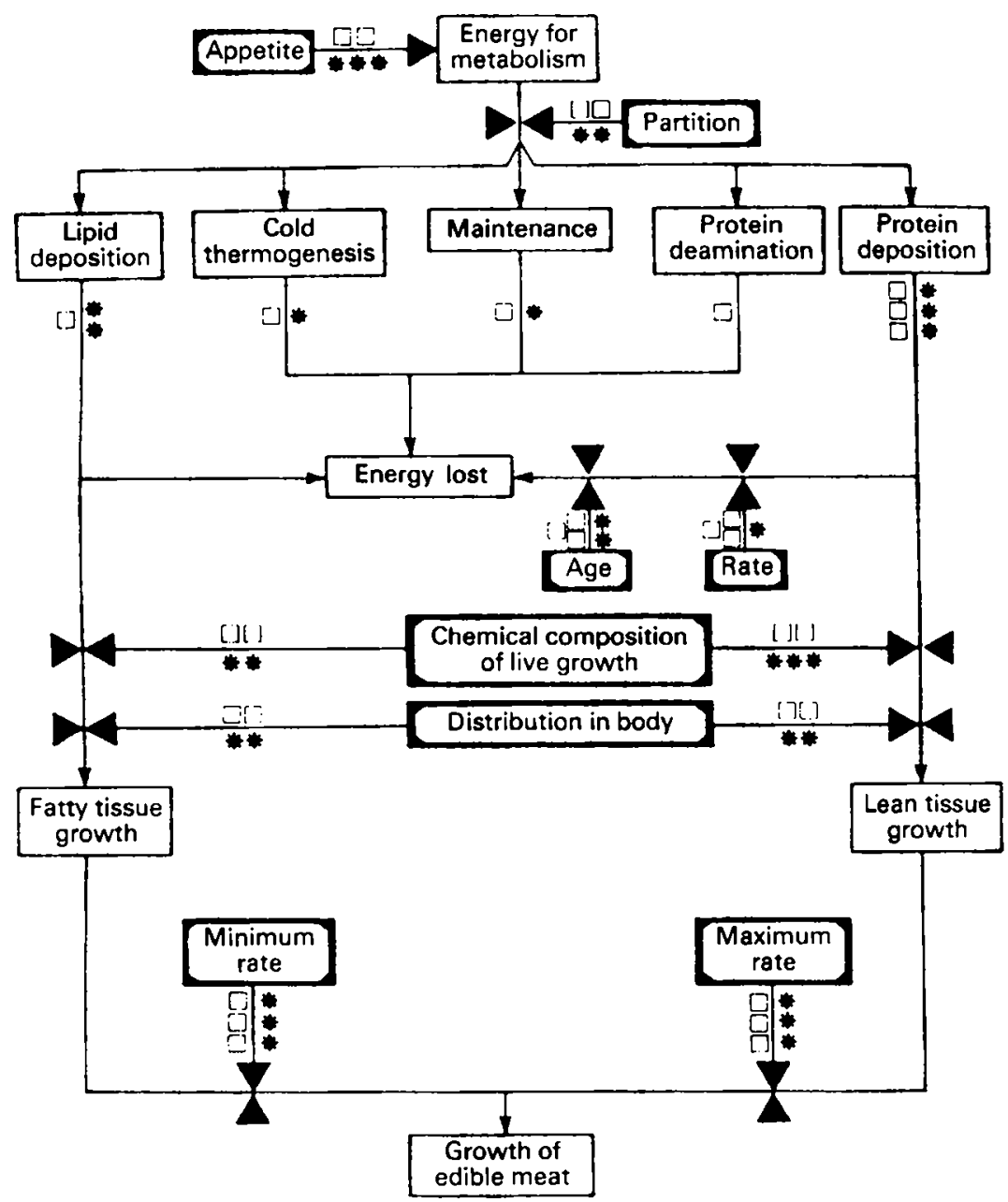

Fig. I. Flow diagram for conversion of food energy into edible pig meat. Some factors involved in the determination of nutrient requirement are shown together with their extent of importance $(*)$ and the level of ignorance ( $\square$ ) pertaining to them.

Research workers, planning experiments first in areas which are feasible, are unlikely to have chosen to examine particular problems on the basis of their importance within the context of a complete model. But for a model to work, an unbroken information string between input and output is required. Models are therefore particularly appropriate for demonstrating gaps in knowledge and elucidating those matters which require very detailed information and those for which approximation is good enough. Fig. I, using energy requirement for growth as an example, indicates some of the factors involved together with the level of ignorance relating to them and their extent of importance. Ideally, "**' (high extent of importance) would be matched by ' $\square$ ' (low level of ignorance) and vice versa. 
Within the context of the determination of nutrient requirements, models can range from an empirical regression of live-weight gain on food intake derived from farm data, through to a deductive sequence of mathematical descriptions of cellular biochemical reactions and intestinal fluxes. The first type is static and inflexible; the input information and form of output are not sufficiently well defined either to give a satisfactory prediction of response without the circumstances in which the data was collected, or to illuminate the nature of the response. The second type is currently too speculative and, as a working model of reactions in live pigs, contains an unduly high proportion of hypotheses to hard findings.

Some current models take the middle ground, with objectives: (1) to give response prediction in terms of useable output such as dissected fat and lean, backfat depth, live growth rate, efficiency of nutrient use, numbers and weight of offspring; (2) to accept inputs in terms such as digestible energy, digestible crude protein (nitrogen $\times 6 \cdot 25$ ), amino acids, proximate food analysis, pig type and sex, environmental conditions; (3) to tolerate some hypotheses and allow their examination, for example, the effect of rate of growth on the cost of growth, the presence (or otherwise) of maximum limits to the daily rate of protein deposition and minimum limits to the daily rate of lipid deposition. The greater the gap between the body chemistry factors (energy cost of protein deposition, maintenance, energy cost of lipid deposition) and live products (carcase meat and financial value), the more likely it is that empirical relationships are unavoidable. However, with respect to modelling nutrient use, a factorial or deductive approach is prerequisite if the model is to be truly informative at either the practical or scientific levels. But which is empiricism and which deduction is subjective. Thus, to a cellular biochemist the concept of energy cost of protein deposition is empirical, while to a pig producer, or even some determiners of nutrient requirements, it is factorial and deductive. The more empirical the data, often the more dependable it appears, and it is indeed the situation that factorializing will always be an unsatisfactory exercise in that it cannot, in the foreseeable future, ever go back to the logical source. Thus, after rejecting feeding trial data on the basis of inflexibility, it is possible to be pressured into selecting single values for energy cost of protein deposition and maintenance; knowing them to be inadequate, but lacking sufficient data to allow for possible effects of age, lean mass, lean tissue growth rate and protein turnover.

Because computer models use hard numerical values, they depend upon currently available information and cannot move beyond its boundaries. A model should not create new data, although it may help to form impressions about the nature of prospective data, and will illuminate the consequences of placing together two previously loosely-connected factors.

Because of lack of information, factorial models can take little account of disease, vitamin and mineral requirements, or the effect of food additives. Empirical data measuring response, but not its causes, are not so reticent; although, thereby, they are prone to error. Again, factorial models have, to date, been unable to 


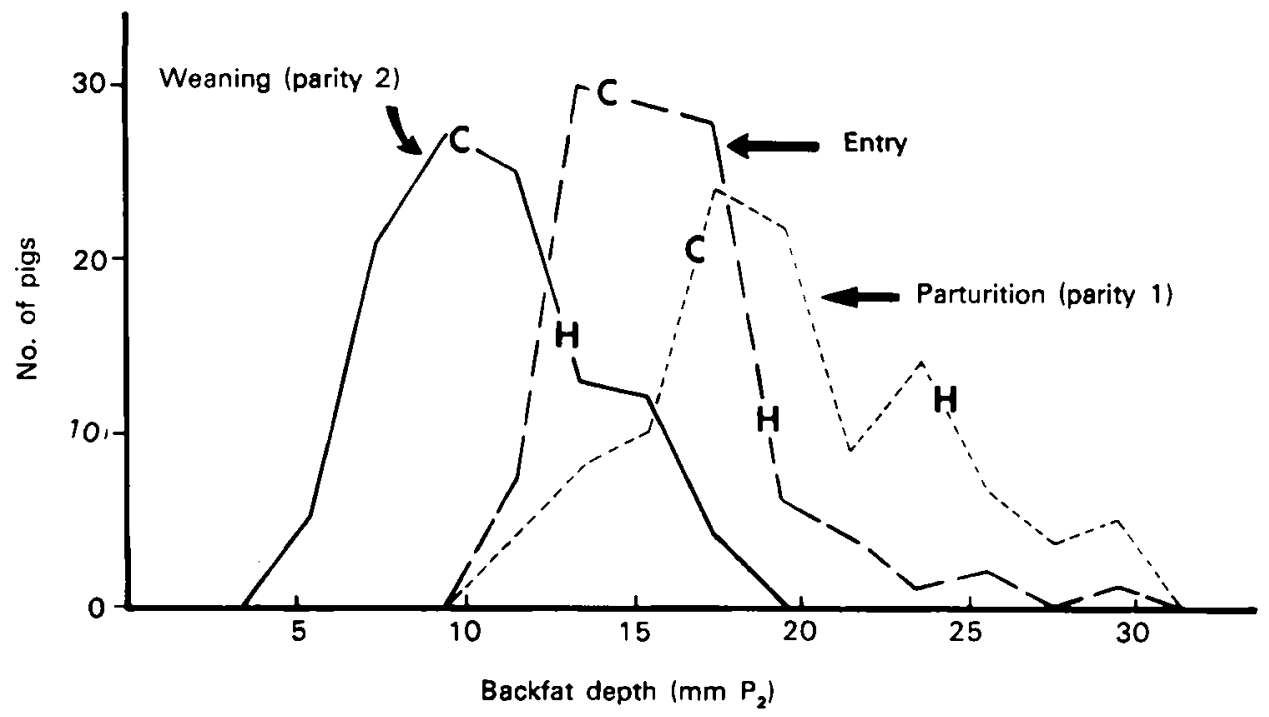

Fig. 2. Distribution of fatness amongst breeding sows on the same nutritive regime and under the same conditions of management. $\mathrm{C}, \mathrm{H}$, mean values for two white strains.

satisfactorily deal with negative or compensatory tissue growth; and will continue to fail in this respect until the relationships between lipid losses, weight change and protein anabolism are better quantified and understood.

\section{Some problems of modelling nutrient requirement}

Nutrients are required for particular purposes and used in particular ways according to the circumstances of their provision. As purposes, modes of metabolism, environment and end-product are all expressible over a wide feasible range, it is unlikely that any one statement of requirement would be appropriate for use in a generalized way. Fig. 2 shows the distribution of fatness amongst breeding pigs when all animals, from the time of entry onwards, were presented identical allowances of the same diet (MLC, unpublished results). The precise purpose of offering a particular allowance of nutrients to sows is often not clarified, but if it were to maintain a certain level of body fatness or condition, then that purpose was not attained. Improved definition of production environment and endproduct required is a necessary preliminary to a more exact statement of nutrient requirement; notwithstanding the need for information on the influence upon nutrient metabolism of the circumstances of the production process. The more closely satisfied the objective of matching nutrient supply to product requirement, the more likely it is that there will be a wide range of nutrient requirements used through the pig industry. The precision of the statement for nutrient requirement depends on the exactitude of the definitions of the animal being fed (for example, sex, strain and environment), the metabolism of the nutrients (efficiency and partition), and the end-product required (growth rate and carcase quality). Factorial models represent a convenient way of collating the known factors 
influencing nutrient requirement, and deriving the particular needs appropriate to particular circumstances.

The lean tissue growth response. The constraints imposed upon the relationship between nutrient supply and lean tissue growth rate are fundamental to the estimation of nutrient requirement. Efficiency of nutrient conversion to lean, partition of nutrients between lean, fat and maintenance, and the limits to lean growth potential are prime factors. The slope for the regression of lean tissue growth rate $v$. nutrient supply may be elevated if maintenance costs were reduced, efficiency of conversion improved, or fewer nutrients were diverted to fat deposition. There is some evidence that maintenance costs may differ between breeds and sex (Okwuosa, 1971; Sharma et al. 1971; Houseman, 1972; Lister et al. 1974). A fixed food-fixed time comparison of the Selected and Control lines at Newcastle University also indicated that, while being less fat, the Selected line does not deposit proportionately more protein (Henderson et al. 1980). A similar phenomenon has appeared in some commercial stocks. The possibility of a reduction in the energy cost of protein deposition, or an increase in the efficiency of protein transfer from diet to lean meat, is even more speculative. It has been argued (Whittemore, 1976), but not substantiated, that energy cost may increase with increasing rate of protein growth and advancing age. Pig type and sex may influence the partition of nutrients between lean and fat growth (Wood et al. 1979). The fixed food-fixed time trial at Newcastle suggested the lipid:protein

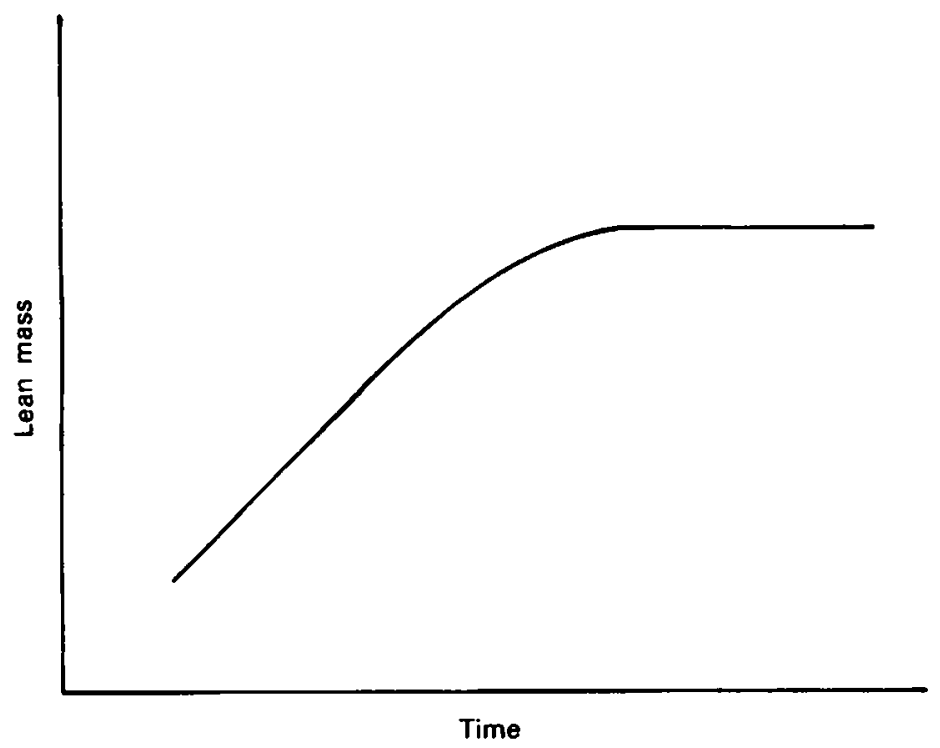

Fig. 3. Relationship between lean mass and time. ( $\mathrm{I}$ ) if there is no consequence for time at maturity of a change in mature lean mass, then lean tissue growth rate is a function of mature lean mass; (2) if there is no consequence for mature lean mass of a change in time at maturity, then lean tissue growth rate is a function of time at maturity. 


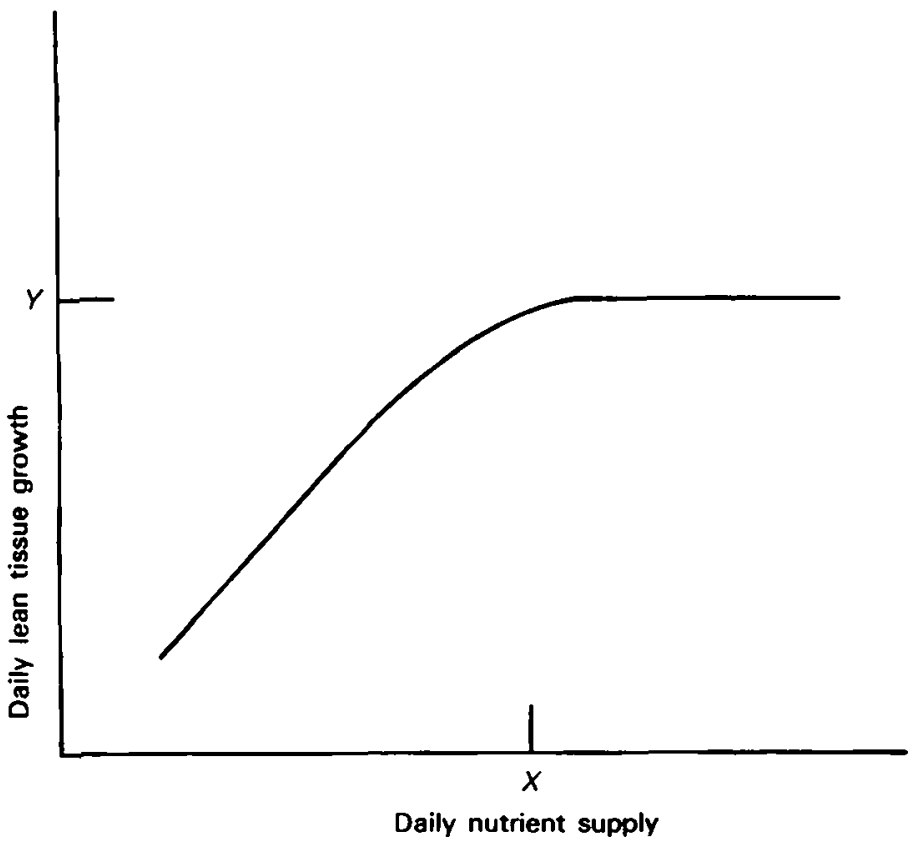

Fig. 4. Relationship between lean tissue growth rate and nutrient intake. ( 1 ) if nutrient intake (appetite) ranges below $X$, then lean tissue growth rate is a linear function of nutrient supply. If nutrient intake ranges above $X$ then lean tissue growth rate is unrelated to nutrient supply; (2) if the limit to lean tissue growth rate is less than $Y$, then at nutrient intake $X$ lean tissue requirements are exceeded. If the limit to lean tissue growth rate is greater than $Y$, then at nutrient intake $X$ lean tissue requirements are not met. If two animals have lean tissue growth limits of $Y$ and greater than $Y$, then those differences will only be evident at nutrient intakes greater than $X$; (3) a change in the regression of lean tissue growth rate on nutrient supply (within the bounds of $X$ and $Y$ ) could be caused by; a change in maintenance requirement, a change in the efficiency of nutrient use for lean growth, or a diversion of nutrients from fat growth to lean growth. There will be a concomitant change in the nutrient requirement for lean tissue growth rate. If a change in the regression of lean tissue growth rate on nutrient intake has little consequence for $Y$, then nutrient requirements for maximum lean tissue growth rate will be reduced as the regression slope increases.

values for Selected and Control lines to be $\mathrm{I} \cdot 3$ and $\mathrm{I} \cdot 5: \mathrm{I}$ respectively (Henderson et al. 1980). By definition, an improved animal is one which diverts nutrients from fat growth to lean growth; with the possible corollary that different pig strains demand different levels of fat in the gain.

Although it seems inescapable that there must be some genetically-defined limit to the daily rate of protein deposition and lean tissue growth rate, there is disagreement as to whether this limit is reachable within the limits of appetite (Fowler et al. 1979). Growth rates of dissected carcase lean tissue for pigs given a generous food allowance appear to range between 200 and $300 \mathrm{~g}$ daily and be dependent upon age-weight, sex and strain (Kielanowski, 1969; Thorbek, 1975; MLC, 1977). The MLC (1977) results suggest that a difference of approximately $30 \mathrm{~g}$ lean tissue growth daily exists between the top and the bottom of the range of 
pig types tested. It remains unresolved whether the age-weight effect is such, or more properly a nutrient intake effect. Recently it has been shown (Tullis \& Whittemore, 1980) that high food levels in early life can sustain high lean tissue growth rates. Kielanowski (1969) suggested limits to the daily rate of protein deposition in the whole live body to be $100 \mathrm{~g}$ for castrated males, $112 \mathrm{~g}$ for females and $\mathrm{I} 30 \mathrm{~g}$ for boars. J. E. Riley (unpublished results) has found similar values (8o, 110 and $13 \circ \mathrm{g}$ respectively) to apply in practice. Using the approximate factor of 2.53 between lean tissue growth rate and protein deposition (interpolated from R. Braude \& J. S. P. Costa, unpublished results) these values are consistent with lean tissue values. Dissection results from boars of the highest genetic merit would indicate protein deposition rates in the region of $160-170 \mathrm{~g}$ daily.

Factorial modelling suggests that the next steps in enabling more accurate determination of nutrient requirement are held up by shortages of information at two levels. First, hard numerical data are needed about the nature of the biochemical reactions controlling energy and protein metabolism, so that, in particular, protein turnover and its ramifications can be quantified. Secondly, results are required from tests of the various plausible hypotheses which could describe the controlling forces of lean tissue growth. Figs. 3 and 4 raise some of the contenders. They serve to demonstrate not merely the difficulties inherent in model building, but also thereby the dangers of generalized recommendations of nutrient requirement.

Determiners of nutrient requirements of pigs currently require to have feet in two camps, that of the 'feeding trial', or empirical, school, and that of the 'factorial', or deductive modelling, school. Dr R. Braude has been instrumental in ensuring that the best of each approach is enacted to the benefit of the animal feed and pig production industries. Both the type of work described, and the author himself, owe much to his encouragement.

\section{REFERENCES}

Fowler, V. R., Close, W. M., Fuller, M. F. \& Whittemore, C. T. (1979). 8th Symp. Energy Metabolism, Cambridge. (In the Press).

Henderson, R., Ellis, M., Smith, W. C. \& Whittemore, C. T. (1980). Anim. Prod. (In the Press).

Houseman, R. A. (1972). PhD Thesis, University of Edinburgh.

Kielanowski, J. (1969). Rota cubana Cienc. Agric. 3, 207.

Lister, D., Wood, J. D. \& Perry, B. N. (1974). Proc. 25th A. Mtg Eur. Ass. Anim. Prod., Copenhagen.

MLC (1977). Commercial Product Evaluation Report. Years I-3. Bletchley: MLC.

Okwuosa, B. N. (1971). PhD Thesis, University of Leeds.

Sharma, V. D., Young, L. G. \& Smith, G. C. (1971). Can. J. Anim. Sci. 51, 761.

Thorbek, G. (1975). Beretn. St. Husdyrbrugsforsøg, Kobenhavn no. 424.

Tullis, J. B. \& Whittemore, C. T. (1980). Anim. Prod. (In the Press).

Whittemore, C. T. (1976). Proc. Nutr. Soc. 35, 383 .

Wood, J. D., Lodge, G. A. \& Lister, D. (1979). Anim. Prod. 28, 371. 